\title{
Speculative Cultural Constructs of the Human Condition in John Fowles's Mantissa
}

\section{Tibor Tóth}

Tibor Tóth is Associate Professor at the Department of English Studies of Eszterházy Károly University College, Eger, Hungary. He offers courses dedicated to romantic, modernist and postmodernist literature and culture. His current research focuses on contemporary literatures in English, with emphasis on the fiction of John Fowles and Philip Roth.

\begin{abstract}
In Mantissa, Miles Green is deprived of his identity, and his Muse(s) attempt to help him reforget it through different (sub)cultural impersonations. This privately coded novel presents the process, which results in what could be termed a culturally determined variant of the postmodern human condition. My paper discusses some aspects of the way in which John Fowles reformulates his interpretations of the postmodern human condition, while demonstrating the capacity of art in general and of the novel in particular to adjust its rhetoric, narrative and technical solutions to the expectations generated by this extremely complex and difficult task.
\end{abstract}

When John Fowles published Mantissa in 1982 most critics agreed on the thesis that he had endeavoured to sum up his earlier approaches to the theme of the human condition in the second half of the last century. Pamela Cooper in her excellent survey of John Fowles's works entitled The Fictions of John Fowles, Power, Creativity, Femininity asserts that the novelist's latest work repeats themes more convincingly formulated in his earlier works, but observes the original quality of the artist's handling of his material in Mantissa.

"As a whole, Fowles's latest work implies an effective backtracking with regard to narrative technique, a thematic reassertion of the power of the artist (although Mantissa is ambiguous in both these respects), and a reconfirmation of the woman in her passive, instrumental role relative to art, language, and narrative. These last three books may be identified, therefore, in terms of the fictional possibilities they refuse, and considered as a collective "road not taken" (Cooper, 1991, p.193).

Mahmoud Salami in his book entitled John Fowles's Fiction and the Poetics of Postmodernism formulates the thesis that the novel foregrounds the subjective authority behind the illusion of objectivity and defines the novel as a book which is about nothing else but itself. "By and large Mantissa is a novel that challenges its own narratological making. Indeed it is a linguistic fantasy, a self-contained text that reflects nothing but itself" (Salami, 1992, p.191).

This also foreshadows the fact that that the human condition is discussed primarily from the aesthetic point of view. Katherine Tarbox is more enthusiastic about the novel and she praises John Fowles for the spirit of exuberant playfulness and the well-developed sense of comedy and continues by asserting the possibility that the novel might have been too playful for its 
critics. Katherine Tarbox discards some of the terminology employed by theory when describing the kind of fiction John Fowles offers us in Mantissa.

"The plot is constantly being rewritten before our eyes by the characters themselves, who change both shape and identity with the snap of the finger. The only thing that is sure is that the action (if indeed action can be said to take place inside a brain) represents the monumental struggle between the author and his protean Muse, whose actual existence is highly suspect" (Tarbox, 1988, p. 120).

Indeed, the status of the characters and their (super)human condition(s) are constructed out of re-forgotten influences that might have determined the then state of the author's mind. The plot of the novel takes place inside a brain and it takes the form of an elegant (inter)play of the pragmatic, existentialist, absurd, humanist, liberal interpretations of the human condition in the form of a spiritual journey. This strategy seems to fit perfectly the mainstream of "revolt against method" of the period. Patricia Waugh in her excellent book entitled Harvest of the Sixties, ${ }^{1}$ referring to Popper, Gadamer, Kuhn and Fayerabend, states that both literary culture and the social sciences had adhered to a "marked shift away from positivism" and developed a new taste for meanings constructed through language, and indeed John Fowles also demonstrates not only the above theorem but also the validity of Patricia Waugh's statement which asserts that "in a rationalized world, linguistic ambiguity and indeterminacy might prove more of a virtue than a hindrance, providing spaces in which to open up possibilities for renegotiation, vision, and unplanned process" (Waugh, 1995, p.127).

The space and the strategy devised by John Fowles in Mantissa are ingenious and have a number of advantages. The formula is simple as in Mantissa he opts for an incessant dialogue between an imaginary artist and the different impersonations of his Muse as a technical solution. Objective time is sacrificed even at the level of the narrative and meaningful subjective dimensions anchored in the aesthetic whirls convincingly replace it.

These subjective dimensions are justified through a process John Fowles terms 're-forgetting', which might be treated as the equivalent of the possibility to endlessly renegotiate all the aspects of the human condition and its representations. The question to what end seems to be naturally generated by these continuous rearrangements. The story is timeless as seconds, minutes and hours are replaced by 'pages', with the advantage that the Muse gains the right to confuse the centuries she is speaking about. This means that cultural tradition can be handled quite liberally and the post-war human condition can be interpreted on the basis of the freedom thus attained. Because in the novel freedom is primarily an aesthetic category and its traditional roots can only be interpreted with the above in view, it is only natural that Mantissa examines its material existence much in the fashion formulated by a well-known Descartes quote John Fowles uses as the motto for the first section of the novel. In Descartes' formula the spiritual world declares its independence from the material one, and as it is just logical under the given circumstances John Fowles declares the setting of the novel to be a spiritual one. We land in a ward set in the interior of a fictionally designed skull which is declared the only logical setting for the kind of story we are reading.

The story is predictable and different 'constituents' of the human condition are revealed in the course of a 'spiritual duel' between man and woman, and the 'flexibility' of the plot is shaped and maintained by sex which is the central metaphor of the novel. Random cultural variations help man cumulate the identity of all possible males from Zeus, via Homer, Shakespeare, T. S, Eliot to Miles Green while woman reveals an identity which is constructed and deconstructed through her apparitions as a Greek goddess, the Dark Lady, a punk guitarist, a late $20^{\text {th }}$-century poetess, an agent of Margaret Thatcher, or Dr. Delfie.

The only 'action' that can be described in conventional terms is interpretable as variations on the theme of two characters trying to seduce the other sexually with the intention to dominate 
or rather manipulate their shared and continually re-forgotten condition in a space in which the presentation of the inexplicable becomes a central principle.

The Descartes quotation employed by John Fowles foreshadows most of the relevant explanations:

"I knew that I was a being whose whole existence or nature is confined to thinking and which has no need of place, nor depends on any material thing, in order to exist.

So that this I, that is to say the soul by which I am what I am, is entirely distinct from the body, is even easier to know than the body, and furthermore would not stop being what it is, even if the body did not exist" (No page number).

The situation thus created has a number of advantages as we know the nature of the existence of the 'body' and its relationship with the outside world; consequently, the traditionally relevant aspects that determine the human condition, such as history, social standing, marital status, tradition, (sub)culture, politics, market economy, postmodernism, (post)postmodernism etc., can be examined from the comfortable distance offered by an often changing spiritual platform which incessantly repeats variations of man and woman engaged in sexual congress. The Descartes paragraph also specifies a relevant aspect of the ward which is an inner space - the term interior space could be inadequate - in which anything can happen without being hindered by the influence of the outside world, and this means that separation from the material world is desirable and possible, and ultimately it is a fictional fact.

The 'existence' and the real nature of the characters which populate this spiritual world are reinterpreted through another introductory quotation presented in the form of a motto. The text belongs to Lempiere and is taken from his Musae: "They were generally represented as young, modest virgins, were fond of solitude, and commonly appeared in different attire, according to the arts and sciences over which they presided" (No page number). This means that the setting is 'spiritual' and that the character(s) is (are) kind(s) of variations and 'appear in different attire.'

The time of the action cannot be interpreted in any conventional way either: firstly because the setting has no traditionally interpretable connection with the exterior world, secondly because the passing of time is 'measured' by pages. The general mood or atmosphere of the novel is 'coded' privately as well: it is dominated by 'a luminous and infinite haze.'

The world thus envisaged might be interpreted as a liberal heaven where all the cast-iron rules of the traditionally conceived human condition stumble, fall and vanish. Time, setting, marriage, social and financial standing, career are irrelevant and the 'liberated' space allows for infinite and genuinely unlimited possibilities. Yet the value of all possibilities can only be defined by the worth of the gains they bring to those who endeavour to live by them.

From this perspective the advantage produced by the above situation is at best questionable. The initiatory perspective is obscure as it is formulated in the negative in a very cunning way: "Not language, not location, not cast" (M.3), but the identity of the source of the speaking voice is 'forgotten'. The dominant pronoun is 'It,' or as the text formulates it 'It' was bereft of pronoun: "It was conscious, evidently; but bereft of pronoun, all that distinguishes person from person; and bereft of time, all that distinguishes present from past and future" (M.3).

The protagonist defined by 'It' becomes an 'I of sorts' (M.4) and this 'I of sorts' desires to 'reforget' instead of remember. An exasperated woman who does her best to remind him that she is his wife deepens his sense of identity as an 'It', and the doctor's intervention doesn't help either. All its/his answers continue to be formulated in the negative: "Name! No name. Nothing. No past, no whence or when" (M.5). What is more: "He would have liked to close his eyes, to have peace to reforget, to be once again with the sleeping blank page oblivion" (M.6). In the above situation loss of identity might sound handy, but the dangers of this deconstruction are predictable. 
The other interesting term formulated by the narrative voice is 'blank page oblivion.' 'Blank page oblivion' refers to authentic non-existence as a form of existence, because it refers to a page that can be re-populated. The element of motivation identified at this phase is the desire to regain this 'blank page oblivion' - the possibility to create or experience a new form of human condition. The question is out of what experience, knowledge or reality can a new human condition be constructed. The method and the nature of this process are quite unusual as well. The 'doctor' achieves some progress by challenging it/him with interpretable, memorable 'pages'. Traditional identity is thus replaced by one which is rooted in culture and Miles Green can and does tell her that Pickwick Papers was written by Dickens and $A$ Midsummer Night's Dream by Shakespeare. He can even remember protagonists which exist on those pages: he mentions Bottom and Titania. This is the first step to Miles Green's aesthetic sense of male identity: memories of spiritual power belong to the 'he' who also happens to have a name.

The conversation of Miles with the doctor abounds in subtleties. The detailed description of the room and the discussion about the clock, which does not cuckoo any more, seem to be designed to distract attention from the otherwise relevant information regarding the 'locus.' We are told only many 'pages' later that the grey dome which hosts the spiritual sphere is the skull of the fictional artist. The interior of the skull - which hosts the grey cells, which become after all, the setting, time, and characters of the novel - is defined as a ward. It does not come as a surprise that it is a ward where mental problems are treated. The ward is the platform from which the state of the human condition in the second half of the 20th century will be re-forgotten. In this context it is more than simply interesting that Miles Green even suspects it to be a lunatic asylum on one occasion with the implied possibility that his and his muse's interpretation of the human condition might be a demented one.

The already mentioned 'original' definition of space, time and character allows for an equally 'free' interpretation of the protagonist's identity, which seems to be essentially an aesthetic one, his condition is also a function of the way in which traditional interpretations of culture and his own perceptions of this relationship can bring him benefits, can construct his old/new, or rather eternally reformulated, sense of identity. The pleasure of ignoring or re-forgetting one's identity competes with the fear of the definite loss of identity, so the inherent dichotomy becomes representative of the controversial aims and methods of liberal thinking.

Yet, John Fowles considers himself a liberal humanist, so consequently his critique is burdened with many elements of uncertainty. John Fowles is interested in the effects of liberal thinking on the human condition, but he demonstrates some sense of bitter irony with regards to liberal thinking on a number of accounts. Less elegant and subtle critiques of liberal thinking were produced in "Poor Koko," a brilliant short story in which both the artist figure and the young burglar interpret their social and moral obligations quite liberally. The burgled artist invokes physically weak predecessors to gratify his cowardice, while the young burglar justifies his deeds using revolutionary discourse. The core of the conflict, the source for their shared anti-human(ist) condition is explained as the incapacity of the artist (and his generation) to communicate with the emerging new generations and the subculture they live in. In "Poor Koko" following a complicated process of investigation the author formulates the source of the conflict as langue in search of a parole.

In Mantissa, time and setting dissolve the boundaries between the real world and the worlds of the protagonists' imagination. Space is identified in terms of spiritual reflection of the idea of space contained in a ward-like skull where both Zeus and Margaret Thatcher can have a role, time is measured by the pages we are reading, and some of these pages are from the Odyssey, others from marketable bestsellers or from essays on literary theory. The protagonists pretend to be ignorant of the situation and their own statuses and some sort of meaning(s) is in search of ways of being comprehensively articulated. Yet the meanings and 
the possibilities of articulating them cannot be properly formulated either, so Miles Green has no other choice than to return to his initial state.

Re-forgetting, the central organising principle of the novel, is maintained in its down-to-earth status through sex. Sex, the central metaphor of the story is the only constant element of the novel. Dr. Delfie's curious therapy shocks and horrifies the 'patient', who tries to retain decency and respond to temptation simultaneously, yet it is impossible to ignore the fact that the 'rape the other way round' is his/its (the artist's/the novel's) central metaphor of the creative process in which the Muse is trying to inspire the artist to discover a new identity for himself.

In The French Lieutenant's Woman Folwles declares that $20^{\text {th }}$-century writers are not interested in authority but in the kind of freedom which allows for other freedoms to exist; but Miles Green, the artist who lives in the brain of the postmodern artist claims that he deserves more equal possibilities. Yet the postmodern male's condition is conditioned by his female counterpart's condition. Mahmoud Salami explains this situation quite convincingly when he tells us that the freedom of the Muse is both desirable and avoidable in the context of the novel.

"In Mantissa the woman figure is constructed as the fertile mother, the mystic virgin, the attainable muse for the recreation of Miles's own subjectivity, and the "lacuna," the linking space among his split imagination, his divided self, and his fragmented texts [...] Miles's subjectivity seems trapped within the textual limits of his fantasies [...] that is why he wants to free himself from the determination of the author [...] he wants to achieve unique identity rather than to remain as a device in someone else's text"2 (Salami, 1992, p. 213).

The model seems complete by the end of the first section of the novel and different aspects that might determine the quality of the human condition are examined on the basis of the reforgotten (sub)cultural experiences which invade the book.

Commenting on Gadamer's Truth and Method Patirica Waugh writes the following: "His views, though expressed mainly in relation to scientific knowledge, were remarkably similar to T. S. Eliot's notion of tradition as a necessarily inarticulable condition of being: one can live in or embody it, but once fully articulated, tradition ceases to be. In his famous essay of 1919, "Tradition and Individual Talent", as in the later cultural criticism, had attacked rationalized social planning by defending the importance of tradition in preserving a socially vital, but necessarily unconscious and tacit, cultural knowledge" (Waugh, 1995, p.131).

When John Fowles re-forgets cultural knowledge he gains the right to critically reassess the relationship between the postmodern condition and randomly chosen fragments of tradition. The Muse, who is Erato, Dr. Delfie and Nurse Cory, vanish(es) and Nemesis, a punk guitarist takes their place. Her discourse sounds convincingly contemporary as she calls Miles Green a 'bastard, fuckin' chauvinist pig,' and announces that she considers the first section of the novel 'elitist crap.' This threatening embodiment of contemporary subculture embarrasses the artist who has no other choice but to tame the $20^{\text {th }}$-century variant of the Muse by 'reforgetting' her into a more traditional status, and as a result the woman wearing the symbols of three contemporary subcultures metamorphoses into an archetypal muse.

"Her right hand begins to pick a scale, a remote one, the Lydian mode. The transition is melting rather than instantaneous, yet extraordinary. ... (an) unmistakable and immemorial divinity" (M.57).

Yet this re-forgotten dreamlike figure is the daughter of Zeus and requires a full, proper formal apology or she will ask for divine revenge. Indiscriminate respect for antiquity is deferred by a famous literary experience, namely that of James Joyce's Ulysses.

In fact the apparition of Nemesis in the novel breaks the noble or rather not so noble isolation of the interior space however carefully it was designed. Theories, the thesis of cultural history, and the condition of the humanities in Margaret Thatcher's Britain invade the grey 
dome. Art and creativity do not exist in themselves. Miles Green and his Muse have to discuss virtually all the essential determinant factors of the human condition, although it is true that they can select these factors on the basis of their (the factors') relevance to their spiritual coexistence. Classical culture and mythologies are re-forgotten in a fashion characteristic of postmodern times. The Muse tells Miles Green that her divine family considers contemporary fiction to be a huge joke, and she declares that contemporary theories of fiction are worse than the worst joke ever invented. She speaks about the death of the novel, about market-oriented cultural policy and considers herself a 'poor old milked-out cow'; she enlists topics that might meet contemporary taste such as politics, abortion, street violence, nuclear disarmament and ecology.

She even writes a hideous bestseller, and this 'poor old milked-out cow' inspires solutions that she thinks would make the book marketable. She could become a nun, because the Vatican scenes sell well; the businessman could go to Rome for the beatification ceremony with his new lover, a gay one, because 13 per cent of the readers of English-speaking books are gay, and because Catholics represent 28 per cent of readers; the businessman has to be a Catholic and the last scene would show the statue of the Muse, or lady poet, or rather a nun and the businessman would place unripe bananas at the feet of the statue in secret.

Her 'fiction' actually prostitutes through the 'symbols' she uses the very nature of the metaphor which supports the greater narrative context in which they exist and to counterbalance the exasperating condition in which they landed. Miles Green attempts to explain to her the essence of postmodern art, fiction and ultimately the nature of the human condition in the second half of the 20th century.

The Muse is told that serious modern fiction is about fiction and does not allow for real life, or reality, and that in serious contemporary fiction at the creative level the connection between the author and text cannot be deduced, as the deconstructivists have proved. Miles Green supports the theses formulated by this theory on the basis of the miserable state of the human condition.

"You still go on as if the world's a pleasant place to live in. There's no more flagrant giveaway of superficiality or approach to life in general. Every internationally admired and really successful modern artist of recent times has shown it's totally pointless, black and absurd. Complete hell" (M.121).

The Muse listens and re-forgets contemporary and cultural heritage to a form that could match the expectations of postmodern theories: Mrs. Thatcher's Britain is declared to be a 'concentration camp', and when the artist opens the door of the ward he discovers the same room in which his solitary double suffers.

This is what happens in the postmodern world dominated by what the Muse calls the "cheaply iconoclastic spirit of a talentless and self-destructive culture" (M.145). Her pretended ignorance and matching arrogance undermines traditional knowledge of literary history. She seems not to have enjoyed the company of Shakespeare, Milton, Rochester, Shelley, Keats, H. G. Wells, or T. S. Eliot and she even announces that there was a need for the serpent as Adam "just wasn't up to the job" (M.149).

Erato tells Miles Green that she "did once scribble a little something down" (M.171). It doesn't come as a surprise that the 'little something' she is speaking about is The Odyssey. When she 'reforgets' its title as Men, Will They Ever Grow Up? the artist revolts against the attitude of the Muse on a number of accounts:

"'Look, Erato. The games we play in the game, so to speak, are one thing. But more and more you are introducing them into our rest periods. More and more you are making fun of things that are important to me. Like reality. And don't for God's sake tell me again that you're only being what I want. I do not want you like this. All you're being is what you want. And it's getting beyond a joke"” (M. 182). 
Although Erato tells the artist that she does not want to sacrifice her condition and she wants to maintain her style adequate to a divinity, and does not intend to sacrifice her noble standing the closing lines re-forget the whole story. The artist is on his way to regaining his identity and the text results in a novel.

"The oblivious patient lies on his hospital bed, staring, in what must now be seen as his most characteristic position, blindly at the ceiling; conscious only of a luminous and infinite haze, as if he were floating, godlike, alpha and omega /and all between/, over a sea of vapor" ( $M$. 196).

Mantissa formulates its writer's conviction that art is the best means of expressing the complexity of life and especially life as understood by creative-minded individuals. Reinterpretation or 'reforgetting' as a term or principle does not refer to regression, but it is used to formulate progression. Thus life, and the human condition, can be declared complete hell, but re-forgetting it can help us overcome most of the pernicious effects of the postmodern chaos we have to cope with.

Endnotes:

${ }^{1}$ Waugh, Patricia, 1995. Harvest of the Sixties: English Literature and its Background 1960 to 1990.

Oxford: Oxford University Press. p.131

${ }^{2}$ Salami, 1992, p. 213

\section{Works cited:}

Fowles, J. 1982. Mantissa. Boston: Little, Brown and Company.

Fowles, J. 1996. “Poor Koko.” In. Fowles, John, 1996. The Ebony Tower. London: Jonathan Cape. (143-84)

Fowles, J. 1970. The French Lieutenant's Woman. London: Penguin Books.

Cooper, P. 1991. The Fictions of John Fowles. Power, Creativity, Femininity. Ottawa, Paris:

University of Ottawa Press.

Salami M. 1992. John Fowles's Fiction and the Poetics of Postmodernism. London and Toronto:

Associated University Presses.

Tarbox, K. 1988. The Art of John Fowles. Athens and London: The University of Georgia Press.

Waugh, P. 1995. Harvest of the Sixties: English Literature and its Background 1960 to 1990. Oxford:

Oxford University Press.

Tibor Tóth

Eszterházy Károly College

Eger

Hungary

totib@ektf.hu 